\title{
CONGENITAL STEATORRHOEA DUE TO PANCREATIC DEFECT
}

\author{
BY \\ MARGARET H. HARPER, M.B., CH.M. \\ Honorary Physician, Royal Alexandra Hospital for Children, Sydney.
}

The cases of congenital steatorrhoea reported in the literature are few. It is therefore of interest to present eight cases with the results of post-mortem examination in four. Two other cases have been previously reported (Harper, 1930). The symptoms common to all these babies were failure to thrive on a normal diet, even on breast milk, and the peculiarity of their stools. These were bulky, frequent and offensive, with a rancid odour and of a pale creamy or pale green colour. In most of the cases oily material was passed with the stool and separately. As the children became older, x-ray examination of the bones showed osteoporosis, teeth were badly developed, anaemia became evident, sometimes of the macrocytic type, and there was great susceptibility to respiratory infections.

\section{Case records}

The histories of the eight cases reported here are as follows :

Case 1. E. L., a female infant, was first seen at the age of ten weeks. The only other child of the family was a healthy boy five years old. The mother stated that the pregnancy and confinement were normal. The family history was good. The baby's birth weight was $5 \frac{3}{4} \mathrm{lb}$. Her weight at ten weeks was $7 \frac{1}{2} \mathrm{lb}$. and her height $19 \frac{1}{2}$ inches. The history was that the baby had had frequent green motions from birth, sometimes as many as fourteen, usually seven to eight daily. The motions were large and offensive. A stool seen at the consultation was pale, greenish yellow, with a rancid odour. The baby was breast fed and gained from 2 to $4 \mathrm{oz}$. a week. The appearance of the baby, the history and the appearance of the stool led to a provisional diagnosis of congenital pancreatic steatorrhoea being made. The breast feedings were supplemented with a dried separated milk. Reports from her doctor indicated that on the diet with a smaller amount of fat, her motions became less frequent, being reduced to two daily, and she continued to gain weight slowly. When the child began to use a chamber her mother noticed that oily material was passed with the stool. She was seen again at the age of two years and six months. The report from her doctor said that at six months of age she developed otitis media, which persisted for two years. She then had her tonsils and adenoids removed. A few days after the operation she had pyelitis. At this time her weight was $16 \mathrm{lb} .2 \mathrm{oz}$. and her height $30 \frac{3}{4}$ inches. Her fontanelle was closed. Her teeth were almost entirely devoid of enamel. 
She was admitted to the Royal Alexandra Hospital for Children. During her stay the following investigations were made :

1. The glucose tolerance test showed an approximately normal curve, on a slightly high level. Before glucose was given the blood sugar was 90 mgm. per 100 c.c.

\begin{tabular}{|c|c|c|c|c|c|}
\hline$\frac{1}{2}$ hour & after & 171 & $\operatorname{lgn}$ & & ent \\
\hline 11 , & , & 185 & " & ", & ", \\
\hline $\begin{array}{l}2^{\frac{1}{2}} \text { hours }\end{array}$ & , & $\begin{array}{l}152 \\
102\end{array}$ & " & ", & \\
\hline
\end{tabular}

The urine was sugar free.

2. The serum calcium was $8.6 \mathrm{mgm}$. per 100 c.c.

The serum phosphorus was $6 \mathrm{mgm}$. per 100 c.c.

3. Whole blood cholesterol was $80 \mathrm{mgm}$. per 100 c.c.

4. The Wassermann test was negative.

5. X-ray examination of the long bones showed osteoporosis which a later $\mathrm{x}$-ray showed to be more marked.

6. The blood-count showed a marked anaemia with high colour index and many large red cells.

RED BLOOD CELLS, 2,330,000 per c.mm. Haemoglobin, 48 per cent. Colour index, 1. There were numerous large red cells.

WHITE CORPUSCLES, 7,200 per c.mm.

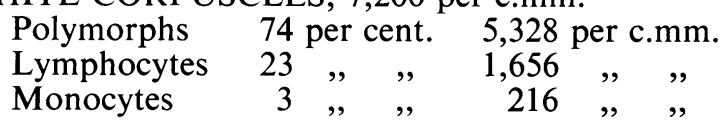

No abnormal white cells were seen.

7. The urine contained pus cells and Bacillus coli.

8. The examination of the stools gave the following results :

The weight of dried faeces of twenty-four hour specimen was $96 \mathrm{gm}$. Faeces were pale, greasy and bulky, with rancid odour. Of the dried faeces 24 per cent. by weight was fat. Of the faecal fat 35 per cent. by weight was split, 65 per cent. was unsplit. In twenty-four hours the child excreted $23.4 \mathrm{gm}$. of total fat, of which $15 \mathrm{gm}$. were neutral fat.

During the early part of the child's stay in hospital her appetite was extremely bad. She was then given injections of insulin before her meals with a marked improvement. She gained weight well, her weight rising from $15 \mathrm{lb}$. to $19 \mathrm{lb}$. in just over a month. Her stools remained the same and her pyelitis did not clear up. The honorary urologist, Dr. Laidley, reported definite urethral obstruction. The bladder wall was hypertrophied. The ureteral orifices were patent and the ureters catheterized without obstruction. Dilatation of the urethra was advised and carried out. The gain in weight was not maintained and the child was taken home to return for further dilatation of the urethra. On discharge her weight was $17 \mathrm{lb} .6 \mathrm{oz}$. and on re-admission six months later it was $16 \frac{1}{2} \mathrm{lb}$. At this time the Pirquet test was positive and the urine from the right kidney showed the presence of tubercle bacilli. There were advanced changes in the lungs and the child died at the age of three years and four months, after a profuse haemorrhage from the bowel, of a generalized tuberculous infection.

The post-mortem examination was carried out and Dr. Tidswell, Director of the Department of Pathology, kindly supplied the following report :

'An emaciated, undersized child with tuberculous lesions in lungs (nodular 
and diffuse, caseous and necrotic with secondary sepsis), spleen, both kidneys, intestines, mesenteric glands and in pancreatic lymph gland. The liver was bright yellow in colour and greasy. Microscopically there were fatty changes, involving all zones of the lobule, but least near the portal areas, most likely consequent on the toxic effect of the tuberculosis. The pancreas was large and looked like a mass of fat, nothing being seen resembling normal pancreas. Microscopically, the whole acinar tissue had disappeared (fig. 1), except for a few remnants of tubules near islets, which themselves, though conspicuous in their isolation, were few and scattered but of essentially normal character. The fatty tissue was of the ordinary type; large clear sacs with a thin cell membrane and a marginal crescentic nucleus. In places some less mature cells showing various degrees of fat accumulation, representing stages of fat formation in connective tissue cells. There was no fibrosis. The appearances suggested fatty replacement of atrophied or undeveloped pancreatic tissue.'

Case 2. L. S., female, was under observation from the second day of life. The mother was unmarried and died from post-partum haemorrhage. The

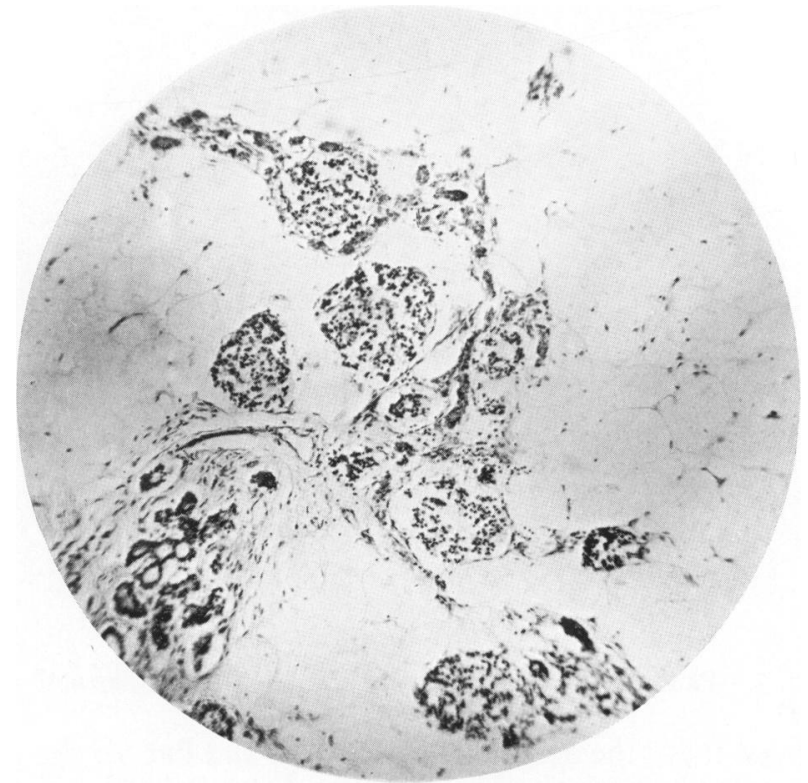

FIG. 1.-Pancreas of case 1, showing islets of Langerhans and scanty acinar cells. Pancreas made up mostly of fatty tissue.

baby was a small, apparently healthy child. Her weight when one day old was $5 \mathrm{lb}$. $4 \mathrm{oz}$. She failed to gain in weight when taking 60 calories per lb. body weight of breast milk. Her stools after meconium had been passed were pale green or pale creamy yellow with an offensive rancid odour. The stools were frequent-from five to ten daily-and some were unusually large. The total amount of faeces passed in the twenty-four hours was considerably larger than normal. The greasy, pale, offensive and large stools and the failure to gain in weight suggested that the baby might be suffering from a congenital pancreatic lesion. When she was a month old, a specimen of her faeces was examined at the Royal Alexandra Hospital for Children. The report was as follows : ' Fatty greenish stool-biliverdin present. Microscopically numerous fat 
globules were seen, but no soap plaques. Total fat was 59 per cent. of the dried faeces. Of the total fat 82 per cent. was unsplit.'

After this examination was made the baby was given separated milk acidified with lactic acid with the addition of carbohydrate in the form of corn-cob syrup. At this time she weighed $4 \mathrm{lb} .12 \frac{1}{2} \mathrm{oz}$. She was given 57 calories per lb. body weight and on this food she made her first gain. She weighed $6 \mathrm{lb}$. when she was two months old. The stools retained their pale greenish yellow colour but diminished in size and number. When she was two-and-a-half months old, she developed broncho-pneumonia and died in the Royal Alexandra Hospital for Children. At the post-mortem examination the liver was found to be normal in appearance. Microscopically, there was patchy distribution of fatty infiltration. There were areas of haemopoiesis. The pancreas was rather small, weighing $2 \mathrm{gm}$. Dr. Tidswell's examination of sections from the

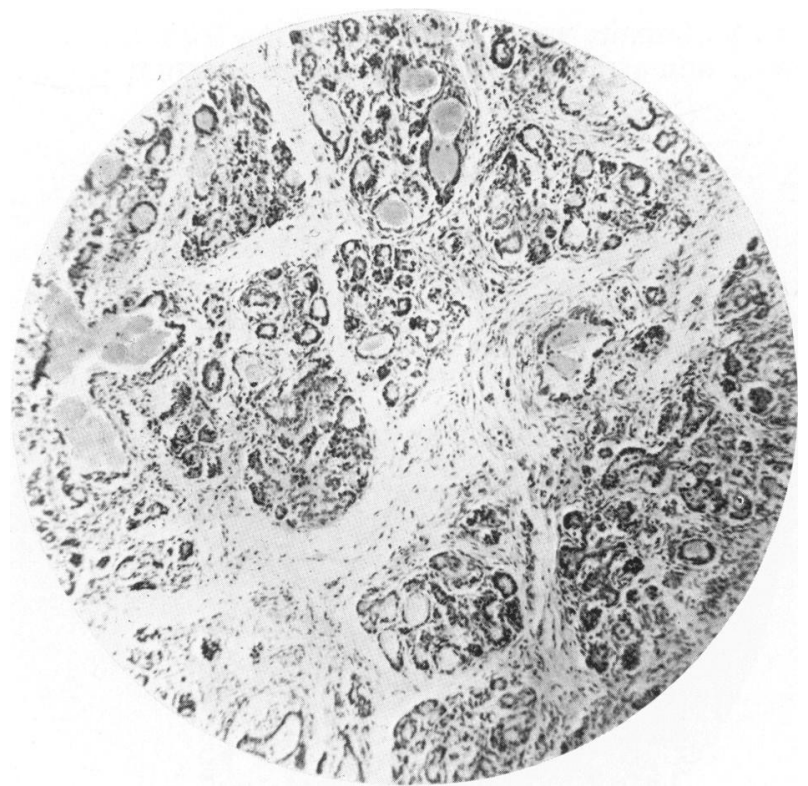

FIG. 2.-Pancreas of case 2, showing fibrosis of trabeculae and acini.

pancreas showed that 'the acinar cells are small and flat for the most part and destitute of a clear inner zone. The ducts are distended but not much distorted and contain some albuminous material. In the smaller ducts the lining cells are flattened, but become cuboidal and definitely columnar in the larger ducts. The islets are small but of normal appearance. The stroma is increased by well-formed fibrous tissue (fig. 2) showing collagenous fibres and fibroblasts and contains a fair sprinkling of macrophage (endotheloid) cells. There are no inflammatory areas. The increased fibrous tissue is chiefly intralobular. The interlobular tissue, though greater than normal, is relatively less abundant. The indications are of immaturity, affecting primarily or particularly the acinar cells with compensatory fibrosis most conspicuous in the alveolar stroma.'

Case 3. C. M., female, was admitted to the Royal Alexandra Hospital for Children from another institution, where she had been for two months without gaining in weight satisfactorily. She was aged five months on admission. She was the third child in the family. The first was healthy and the second had died 
in the hospital at the age of ten days from 'collapse of the bowel.' The baby had been breast fed for two months, then on a modified dried milk. For the last two months she had been fed on fresh cow's milk modified with a fat emulsion and sugar with the addition of fifteen drops of cod-liver oil daily. The motions were reported to have been oily and offensive. No history was obtainable of the number of motions nor the amount of faeces passed. On admission, the stool was examined. The total fat was 59 per cent. of the dried faeces and of this fat 96.7 per cent. was split. The baby gained weight slowly on lactic acid milk made with whole milk for three weeks. She then developed broncho-pneumonia and died. At the post-mortem examination, apart from the broncho-pneumonia, the only other abnormalities were found in the liver and pancreas. The liver was pale and contained much fat. Microscopically there was marked generalized fatty infiltration. No necrosis nor fibrosis was present. The pancreas weighed $9 \mathrm{gm}$. and appeared normal to the naked eye. Dr. Tidswell's description of the sections from the pancreas is as follows: ' The acini are small and distorted, the cells shrunken and lacking the characteristic clear border. The ducts are distended and distorted into bizarre shapes. The epithelial cells are flattened and many are shed into the lumen. Most of the ducts show some structureless content, apparently albuminous. The islets are small, but essentially normal in character and arrangement, with wide tortuous capillaries. The interstitial tissue is markedly increased, widely separating the acini from one another and forming broad bands round the ducts and blood-vessels. Its cells generally are the usual histiocytes and although absolutely abundant are not increased in proportion to the excess of tissue. But here and there, without regular relationship to ducts or vessels, are masses of reticulo-endothelial cells, a few of which are multinuclear. There are no polymorph cells. In this tissue also can be seen lines of parallel flat cells apparently representing intercalary ducts. Collagen fibres are not marked; the ground substance is hyaline rather than fibrillar. The vessels are congested but show no intimal changes. Whilst it is to be presumed that there has been immaturity of the gland substance followed by fibroid hyperplasia, there are signs that some degeneration is in progress.'

Case 4. D. S., female, was first seen at the age of eight-and-a-half months. Her birth weight was $7 \frac{1}{2} \mathrm{lb}$. and at eight-and-a-half months it was $11 \mathrm{lb}$. $15 \mathrm{oz}$. She had never done well and had been given many different foods with no improvement. She had bulky, pale and offensive stools with oily material passed with the stool and separately. She had sometimes as many as six in the day. She was given a low-fat diet and gained weight, but she was subject to attacks of bronchitis. She died at the age of thirteen months of bronchopneumonia on June 23, 1933. An examination of her stool was carried out in January, 1933. Microscopically there were many neutral fat globules. The total fat was 40.8 per cent. of dried faeces, of which 88 per cent. was split. This examination was carried out when she was on her low-fat diet and probably there was little of the oily material in the specimen.

At the post-mortem examination, apart from the lungs, the only abnormality was found in the pancreas, which weighed $12 \mathrm{gm}$. and was nodular in appearance. Dr. Tidswell reports of the sections of the pancreas : "The acini are few and widely separated by stroma. Acinar cells are essentially normalcolumnar with a clear inner zone bordering a well-defined channel. The ducts are not manifestly dilated and their epithelium is of the normal columnar shape. The islets are conspicuous, sometimes large and of normal structure. Although the stroma is superabundant, it does not form bands and it is not restricted to the alveoli, but it is generally and rather evenly present throughout the gland. Its matrix is more hyaline than fibrous. There are numerous endo- 
thelial cells as well as fibroblasts, and everywhere there is a permeation by cells of lymphoid type, occasionally showing plasmoid features. The suggestion conveyed by the appearances is of immaturity, as in the other cases.'

Case 5. M. O., female, was the second child. The first baby died at twelve days old from an infection of the mouth. The patient's birth weight was $8 \frac{1}{4} \mathrm{lb}$. When first seen at the age of four-and-a-half months the weight was $7 \mathrm{lb} .7 \mathrm{oz}$. The baby was breast fed until one month old. Then she had a complement of fresh cow's milk modified with the addition of sugar of milk and water. She was weaned from the breast entirely at the age of six weeks and given a modified dried milk. The baby had irregular gains in weight. The stools were green and offensive and vomiting was frequent. She was admitted to an institution, where she remained for six weeks, losing weight all the time. When she came under observation she was below her birth weight, dehydrated and frail. Her stools were pale green or creamy yellow, bulky and rancid in odour. Oil was passed with and apart from the faeces. Her urine occasionally contained a small amount of sugar. She was given $10 \mathrm{oz}$. of breast milk and $20 \mathrm{oz}$. of a malted milk. In spite of taking over 70 calories per lb. body weight she only gained $1 \mathrm{oz}$. in a week and remained dehydrated. Her fasting blood sugar was $120 \mathrm{mgm}$. per 100 c.c. She was then given injections of insulin twice daily, and on the same amount of food she began to gain $1 \mathrm{oz}$. a day. Her weight rose to $9 \mathrm{lb} .6 \mathrm{oz}$., when she developed broncho-pneumonia and died.

The report on the examination of the stools at the Royal Alexandra Hospital for Children was as follows: Total fat, $47 \mathrm{gm}$. per $100 \mathrm{gm}$. of dried faeces. Of this fat 63 per cent. was unsplit. The stool examined consisted of liquid oil and large bulky air-containing residue, coloured pale green.

\section{BLOOD COUNT.}

Red blood corpuscles, 2,640,000 per c.mm. Hb., 50 per cent.

C.I., 0.9. White cell count, 18,800 per c.mm.

\begin{tabular}{|c|c|c|}
\hline Polymorphs & 80 per cent. & 15,040 per c.mm \\
\hline Lymphocytes & $15,,$, & 2,820 \\
\hline Monocytes & 5 & 940 \\
\hline
\end{tabular}

Unfortunately no post-mortem examination was permitted. This patient was the only one of the series who had glycosuria at intervals.

Case 6. B. C., male, was the first child of young and healthy parents. $\mathrm{He}$ was first seen at the age of three months because he was vomiting. He was breast fed and gained $13 \frac{1}{2} \mathrm{oz}$. in two weeks and then lost weight. With regulation of the feeding the vomiting ceased, but the passage of large offensive motions was reported. The microscopic examination of the stool showed that it consisted largely of minute fat globules. The total fat of the dried faeces was 45.4 per cent. and in one specimen 60 per cent. of the fat was unsplit and in another 41 per cent. was unsplit. For a while the baby did well and gained weight on a fat-free diet. He then developed pneumonia and died at the age of eight months. No post-mortem examination was obtained.

Case 7. T. P., male, was first seen at the age of seven-and-a-half months. He was the second child, the first having died of pneumonia in his first year. He was breast fed until the eighth month. For his first three months he did well and gained weight. Then he began to fail and a nurse immediately noticed that oil was passed with his stool and apart from it. The stools were bulky and offensive. He was given a fat-free diet, but suffered from frequent attacks of bronchitis and he twice had pneumonia. His stools continued to be large and offensive. He died at the age of four-and-a-half years of broncho- 
pneumonia. The first examination of his stool showed that the total fat content of the dried faeces was 71 per cent. and of this fat 39.5 per cent. was unsplit. On another occasion the report was that there were numerous fat globules present and few fatty acid crystals or soap plaques. The total fat was 54 per cent. of the dried faeces, and of this fat 51 per cent. was unsplit. No postmortem examination was obtained.

Case 8. B. W., male, was the first child of his parents. The mother had an operation early in her pregnancy for retroversion of the uterus and at the

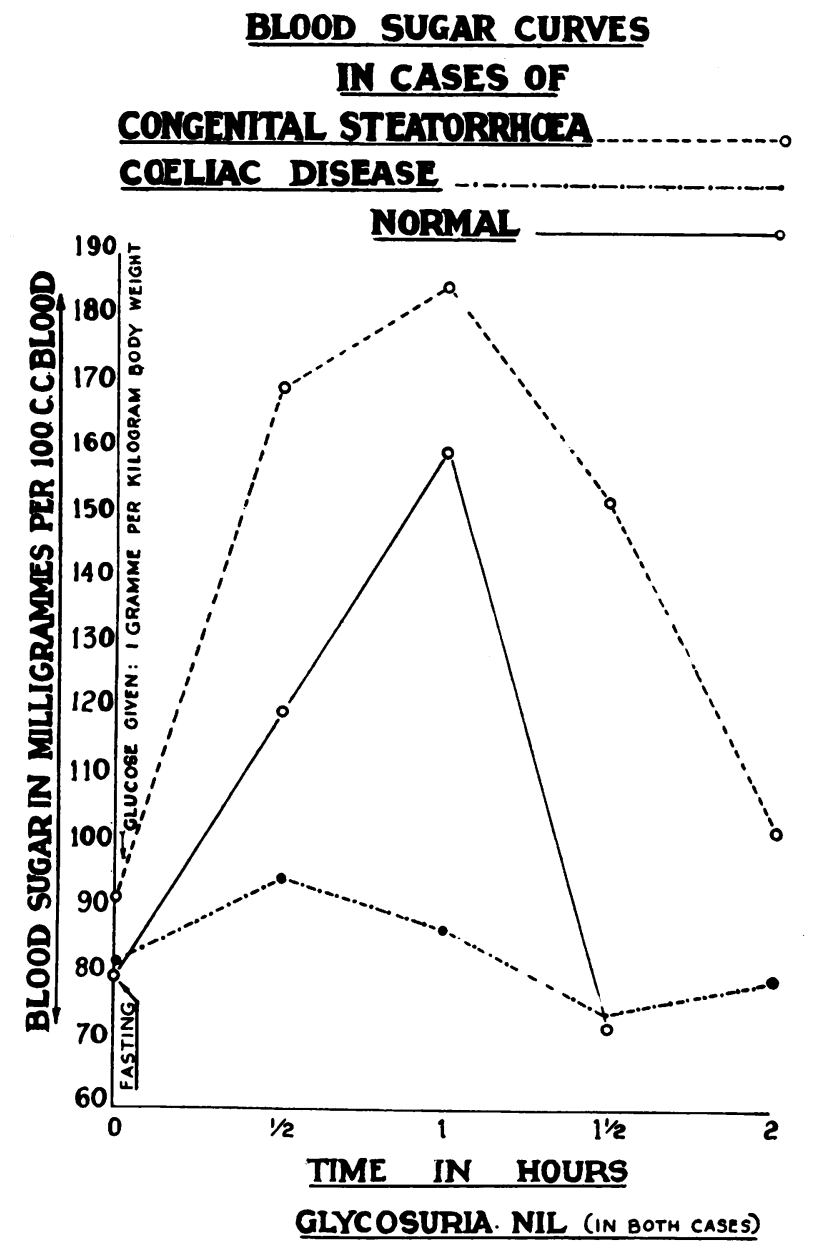

FIG. 3.

same time her appendix was removed. Otherwise the pregnancy and confinement were normal. The baby's birth weight was $7 \frac{3}{4} \mathrm{lb}$. and at the age of six weeks he weighed $6 \frac{3}{4} \mathrm{lb}$. He was partly breast fed for three months and then artificially fed. He was first seen at the age of five months. He had never thrived and always passed large, offensive, pale green stools. From the time he was five weeks old, his mother had noticed that there was oil in his stools. He had been under medical care and was given a dried milk made up to the 
strength of whole cow's milk, egg yolk and biscuit. While on this diet, he vomited and had frequent, large, pale green stools which were rancid in odour. Oil was passed with the stool and between the passing of the motions. The number was usually six a day. He persistently lost weight. He was a thin, starved-looking baby, quite cheerful in appearance. A provisional diagnosis of congenital steatorrhoea was made and he was given a dried butter-milk. While on this food an examination of his stools gave a normal result with the fat well split. On the introduction of whole milk into his diet his stools again became oily. A second examination of his stool was made, this time at the Royal Alexandra Hospital for Children, with the following result : 'Numerous fat globules were seen under the microscope. The total fat was 44 per cent. of dried faeces. The unsplit fat was 59 per cent. of the faecal fat.' The baby was then given separated milk made with a pancreatized starch preparation and was also given a special malt extract. He is at the moment of writing aged twelve months and is gaining weight well, and his stools, although still large and offensive, are a more normal colour and he is not passing oil.*

TABLE 1

\section{FAT CONTENT IN STOOLS}

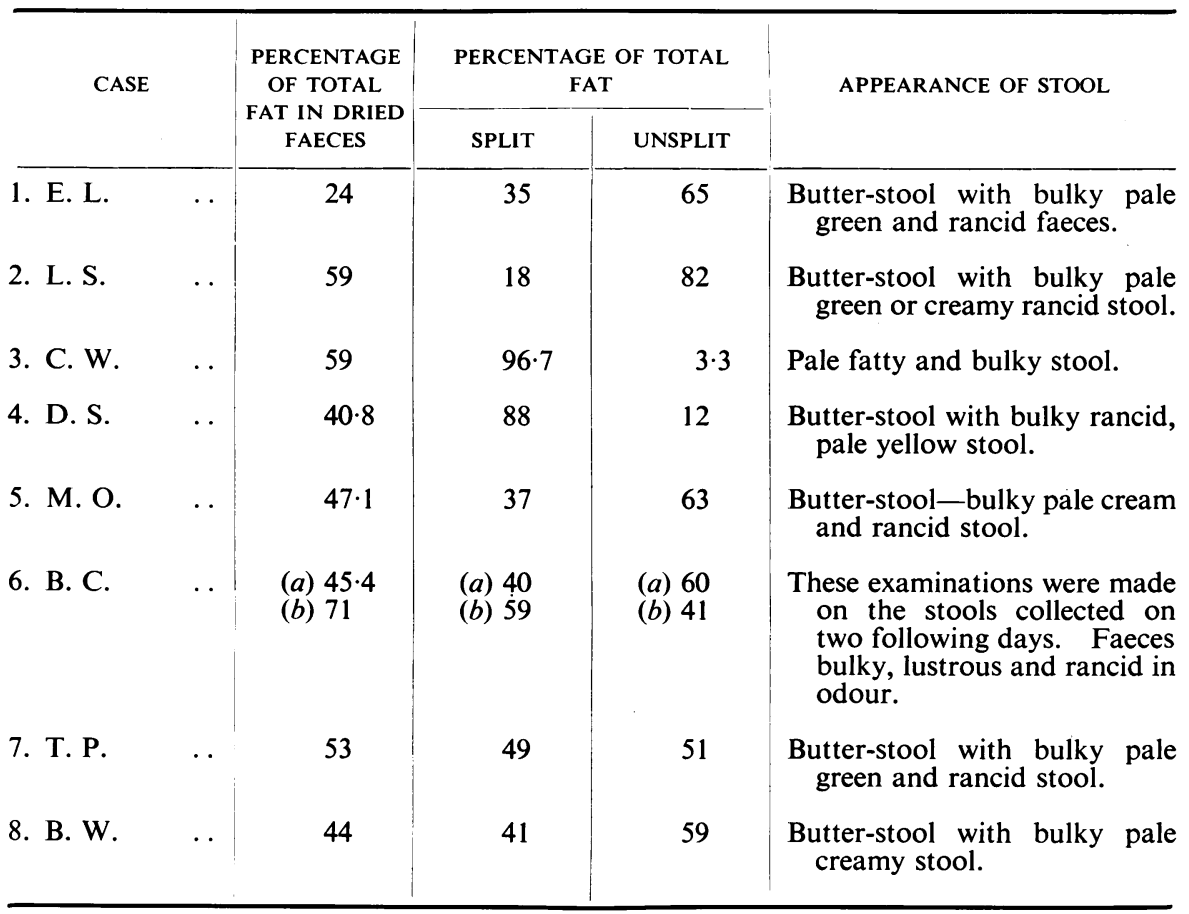

* Since writing this article, B. W. has died at the age of three years. He died from broncho-pneumonia after a prolonged illness. A post-mortem examination was done at the Royal Prince Alfred Hospital. The pancreas appears small and feels nodular. On close inspection numerous semi-transparent cysts of about pin-head size may be seen on the surface. On section the pancreas showed marked atrophy of the acini, with dilatation of the ducts. The islets of Langerhans are relatively normal. 


\section{Comment}

The differences between coeliac disease and congenital steatorrhoea are given in the following table (see also fig. 3) :

\section{CONGENITAL PANCREATIC STEATORRHOEA}

Symptoms present from birth.

Oil is present in the stools (butter-stools).

High faecal fat with large amount of unsplit fat.

Glucose tolerance curve on the high side of normal.

Post-mortem lesions of the pancreas are found.

\section{COELIAC DISEASE}

Age of onset, nine months to two years.

Oil is not present.

High faecal fat, well split.

Glucose tolerance curve flat.

Post-mortem examination shows no lesions of the pancreas.

The signs due to the failure to absorb fat are common to both conditions-such as emaciation, meteorism, anaemia and osteoporosis.

R. Miller (1922-23) clearly defines the various types of fatty stools. $\mathrm{He}$ says :

'Thus we see that there are three types of fatty stool. First, the type of pancreatic insufficiency with a large excess of fat in the stools, chiefly in the form of neutral fat. This condition never occurs in coeliac disease. Secondly, that of excess fat chiefly in the form of fatty acids giving the classical coeliac stools, large, pale, unformed and very offensive. Thirdly, there is the soapy stool, looking normal on casual inspection. It is not offensive and not frequent, yet it may be found to contain anything up to 50 per cent. of fat, chiefly in the form of soaps.'

The patients reported here all gained weight and improved in their general physical condition when they were given a diet containing a considerable amount of protein and carbohydrate and no fat. They were all given a larger number of calories per pound body weight than the number of calories on which babies gain and develop normally. Even after the fat was cut out of their diet, the stools remained larger than normal, although they diminished in frequency. This suggests that the babies were still losing a considerable amount of the food ingested.

H. Morley Fletcher (1934) says : ' Of the three important ferments normally present in the secretion (of the pancreas), it would seem that, particularly in children, the lipase steapsin is the one most liable to show variations in its functional activity as the result of disease of the pancreas. Disturbance of this function of the gland leads to the presence of abnormal quantities of neutral fat in the faeces, giving rise to the so-called "fatty stools," or "steatorrhoea," as it is termed by some authors. It is advisable to restrict the use of the name "steatorrhoea " to the passage of liquid fat with the stools. A congenital form of this condition has been described. The proteolytic ferment trypsin is less commonly affected in pancreatic disease.' 
In case 3 and case 4 the fat in the specimen of faeces examined was well split. In both cases only one specimen was examined. In one ' butter-stools' were present ; in the other they were not noted.

Thaysen (1932) states that in the case of pancreatogenous fatty diarrhoea the so-called 'butter-stool' is usually present, but it was absent in two of his six cases. He also says : "That the greatest part of the fat in the faeces is found in the form of split products (free fatty acids and soaps) is no proof of a normal function of the pancreas, as the same is found even to a higher degree in the pancreatogenous fatty diarrhoea.'

In the analysis of the faecal fat in seven cases of undoubted pancreatic disease, Pratt (1912) found that there was an increase of neutral fat in four.

In the diagnosis of fatty diarrhoea due to pancreatic defect, Thaysen regards the elimination of nitrogen and the glucose tolerance curve as of greater importance than the chemical estimation of the fat content of the faeces. Unfortunately in these cases there was no opportunity for the estimation of the elimination of nitrogen.

As Garrod (1923) says : 'The pancreas, like other glands, is subject to a great variety of lesions, and it is not surprising that in cases of disease of this gland the amounts and proportions of the fatty substances excreted vary widely.'

The cases reported by Clarke and Hadfield (1924), by Burghard (1925), Passini (1919), and Gross (1926) are all similar to those reported here. Julius Hess and Saphir (1935) have recently reported three cases which they call 'coeliac disease.'

In these cases, although the clinical condition is not reported fully, the symptoms were present from birth and in two of them there was a large amount of neutral fat present in the stools. All these died of broncho-pneumonia at the ages of eighteen months, nine months and three years respectively. At the post-mortem examination pancreatic disease was evident. Hess and Saphir say: 'Burghard's, Cross's and Passini's cases, which revealed severe changes in the pancreas, are regarded as examples of coeliac disease.'

This statement is surely incorrect, as they are reported by the authors as examples of disease of the pancreas. The cases of Hess and Saphir evidently also belong to the group of congenital steatorrhoea due to a lesion of the pancreas, and are not cases of coeliac disease.

A. McBryde (1935) reports the case of a child who had had 'symptoms characteristic of coeliac disease from the age of one month' and who weighed $11 \mathrm{lb}$. at the age of twenty-seven months. This child had a hyperchromic megalocytic anaemia. It seems probable that this child also should be placed in this same group.

Clarke and Hadfield (1924) say in the report of their case : 'Several points in the history and physical condition suggested a diagnosis of coeliac disease, in itself an obscure complaint. This diagnosis, untenable on closer clinical observation, was definitely excluded by the post-mortem examination.'

Garrod and Hurtley (1913) reported cases of congenital steatorrhoea occurring in more than one member of a family in which there was no failure of nutrition or other evidence of pancreatic defect. Their patient, seen after an interval of seven years, was a well-grown lad of fifteen engaged in active work. Examination of his stools at this time showed that the anomaly still persisted. 
Miller and Perkins (1920) reported an apparently similar case, but this patient died of broncho-pneumonia and no autopsy was permitted.

Cockayne (1933) reported a case of congenital steatorrhoea which he took to belong to the same group as Garrod and Hurtley's. The facts that the child weighed only $17 \mathrm{lb}$. at the age of a year and ten months and that she died at the age of two years and four months of broncho-pneumonia suggest the possibility that the steatorrhoea may have been due to a congenital pancreatic lesion similar to those reported here. There was no family history in Cockayne's case and two children born subsequently were normal. In the family reported by Soecknick and Thoenes (1927), mentioned by Cockayne, all three children had steatorrhoea. One died of broncho-pneumonia and another of hydrocephalus. Cockayne mentions the high mortality and the frequency with which broncho-pneumonia was the cause of death. He says that this frequency may be only a coincidence, but the fact that in eight out of ten of the writer's cases broncho-pneumonia was the cause of death and in the ninth generalized tuberculosis, seems to point to a greatly reduced resistance to respiratory infections in these cases. The cases reported by Miller and Perkins, by Hess and Saphir and by Burghard also all died of broncho-pneumonia.

In only one of the series of cases reported here was there more than one child in the family affected. The child, a boy, born subsequently to M. O., case 5 , and who is now fifteen months old, is reported by his mother occasionally to pass butter-stools and the stools are always large, pale and offensive. On the only examination of his faeces which has been made, it was found that there was a high total fat present, namely 58 per cent. of the dried faeces was fat and this was well split. This child is at present under observation. Although he is underweight for his age and subject to attacks of bronchitis, he is doing fairly well on a low-fat diet with high protein and carbohydrate.

On reviewing the reported cases of congenital steatorrhoea, that of Garrod and Hurtley seems to be the only one which has attained to an age beyond that of early childhood and who appeared to be of normal physical development at the age of fifteen years. Garrod (1923) says of his case :

'It is tempting, but perhaps not justifiable, to connect this with an isolated failure of one single factor as distinguished from impairment or abolition of the pancreas as a whole.' He also says : 'It must be mentioned that steatorrhoea due to organic lesions of the pancreas may persist for years without grave impairment of the general health.' He mentions the remarkable case of a medical man who died at the age of ninety, having passed butter stools from his sixty-third year. At the autopsy his pancreatic duct was found to be blocked by calculi, and the gland substance was almost entirely replaced by fat.

The consideration of the histology of the pancreas in those cases in which an atutopsy was obtained suggests a failure of development of the gland. Burghard (1925) points out the difference between the histological appearances in those cases which occur in adults caused by obstruction to the excretory ducts and the dilatation and distortion of the ducts which were present in his case and in some of those reported here. He considers that this condition is a congenital one due to failure of normal development of the pancreas.

The conclusion arrived at after reviewing the material available in the literature and the cases reported here is that in cases in which there is evidence of 
the passage of fatty stools from birth (particularly ' butter-stools ') with failure of nutrition, the diagnosis of a congenital defect of the pancreas can reasonably be made.

The author is greatly indebted to Frank Tidswell, M.D., Director of the Department of Pathology, Royal Alexandra Hospital for Children, Sydney, who has given help in discussing these cases and in examining and reporting on the sections; also to Phyllis Anderson, M.B., Ch.M., of the same department, for the examination of the stools and blood; and to Superintendent of the Royal Prince Alfred Hospital for the report of a post-mortem examination.

\section{REFERENCES}

Burghard, E. (1925). Klin. Wschr., 4, 2305.

Clarke, C., and Hadfield, G. (1924). Quart. J. Med., 17, 358.

Cockayne, E. A. (1933). Lancet, 2, 1086.

Fletcher, H. M. (1934). Diseases of Children, by Garrod, Batten, Thursfield and Paterson. Third Edition, 288.

Garrod, A. E. (1923). Inborn Errors of Metabolism. and Hurtley, W. H. (1913). Quart. J. Med., 6, 242.

Gross, F. (1926). Jhrb. Kinderheilk., 112, 251.

Harper, M. H. (1930). Med. J. Austral., 2, 20.

Hess, J., and Saphir, O. (1935). J. Paediat., 6, 1.

Miller, R. (1922-23). Proc. roy. Soc. Med., 16, 22. and Perkins, H. (1920). Quart. J. Med., 16, 1.

Passini, F. (1919). Dtsch. Med. Wschr., 45, 815.

Pratt, J. H. (1912). Amer. J. Med. Sci., 143, 313.

Soecknick, A., and Thoenes, F. (1927). Jhrb. Kinderheilk., 115, 315.

Thaysen, Th. E. H. (1932). Non-Tropical Sprue. 